\title{
Rice Bran Amendment Suppresses Potato Common Scab by Increasing Antagonistic Bacterial Community Levels in the Rhizosphere
}

\author{
Tsuyoshi Tomihama, Yatsuka Nishi, Kiyofumi Mori, Tsukasa Shirao, Toshiya Iida, Shihomi Uzuhashi, \\ Moriya Ohkuma, and Seishi Ikeda
}

First, second, third, and fourth authors: Plant Pathology and Entomology Laboratory, Kagoshima Prefectural Institute for Agricultural Development, 2200 Oono, Kinpo-cho, Minamikyushu-shi, Kagoshima, 899-3401, Japan; fifth, sixth, and seventh authors: Japan Collection of Microorganisms/Microbe Division, RIKEN BioResource Center, 3-1-1 Kounodai, Tsukuba, Ibaragi, 305-0074, Japan; and eighth author: Agricultural Research Center for Hokkaido, National Agricultural and Food Research Organization, 9-4 Shinsei-minami, Memuro, Kasai, Hokkaido 082-0081, Japan.

Accepted for publication 25 March 2016.

\begin{abstract}
Tomihama, T., Nishi, Y., Mori, K., Shirao, T., Iida, T., Uzuhashi, S., Ohkuma, M., and Ikeda, S. 2016. Rice bran amendment suppresses potato common scab by increasing antagonistic bacterial community levels in the rhizosphere. Phytopathology 106:719-728.

Potato common scab (PCS), caused by pathogenic Streptomyces spp., is a serious disease in potato production worldwide. Cultural practices, such as optimizing the soil $\mathrm{pH}$ and irrigation, are recommended but it is often difficult to establish stable disease reductions using these methods. Traditionally, local farmers in southwest Japan have amended soils with rice bran (RB) to suppress PCS. However, the scientific mechanism underlying disease suppression by RB has not been elucidated. The present

ogenic Streptomyces population in young tubers. Amplicon sequencing analyses of $16 \mathrm{~S}$ ribosomal RNA genes from the rhizosphere microbiome revealed that $\mathrm{RB}$ amendment dramatically changed bacterial composition and led to an increase in the relative abundance of gram-positive bacteria such as Streptomyces spp., and this was negatively correlated with PCS disease severity. Most actinomycete isolates derived from the RB-amended soil showed antagonistic activity against pathogenic Streptomyces scabiei and S. turgidiscabies on R2A medium. Some of the Streptomyces isolates suppressed PCS when they were inoculated onto potato plants in a field experiment. These results suggest that RB amendment increases the levels of antagonistic bacteria against PCS pathogens in the potato rhizosphere.
\end{abstract} study showed that RB amendment reduced PCS by repressing the path-
Additional keywords: rhizosphere bacterial community.
Potato common scab (PCS), caused by soil- and seedborne pathogenic Streptomyces spp., occurs throughout potato-growing areas in Japan and around the world. PCS infection damages the skins of tubers and greatly reduces their market value, making it one of the most economically limiting factors affecting potato production (Dees and Wanner 2012; Lazarovits et al. 2007; Liu et al. 1995). In Japan, at least three pathogenic Streptomyces spp. are known to cause PCS: Streptomyces scabiei, S. turgidiscabies, and S. acidiscabies (Kobayashi et al. 2012; Tashiro et al. 2012; Tomihama et al. 2016). Of these species, both S. scabiei (Lambert and Loria 1989) and S. turgidiscabies (Miyajima et al. 1998) are thought to be common pathogens in most Japanese potato cultivation areas (Nishi et al. 2015; Tashiro et al. 2012).

There has been an increasing interest in the utilization of cultural practices as alternatives to pesticides for controlling soilborne diseases (Katan 2000). To date, several cultural practices for controlling PCS have been developed, including optimizing soil pH (Lambert and Manzer 1991; Lacey and Wilson 2001), irrigation during tuber formation (Adams and Lapwood 1978), green manuring (Wiggins and Kinkel 2005), crop rotation (Hooker 1981), and organic amendment (Lazarovits et al. 2001). S. scabiei is able to grow between $\mathrm{pH} 5$ and 8 (Hiltunen et al. 2009; Tashiro et al. 2012). Therefore, reducing the soil $\mathrm{pH}$ to below 5.2 has been recognized as one of the most efficient

Corresponding author: S. Ikeda; E-mail address: sikeda67@affrc.go.jp

*The $e$-Xtra logo stands for "electronic extra" and indicates that 1 supplementary file, 4 supplementary figures, and 10 supplementary tables are published online.

http://dx.doi.org/10.1094/PHYTO-12-15-0322-R

(C) 2016 The American Phytopathological Society ways of suppressing PCS (Lacey and Wilson 2001; Lazarovits et al. 2007). However, regulation of soil $\mathrm{pH}$ is labor intensive and expensive due to soil buffering effects. Irrigation, particularly during the 6 weeks following tuber initiation, has also been shown to reduce PCS (Lapwood et al. 1973) and is a common control measure adopted by growers. However, some studies have suggested that scab levels increased after irrigation (Haynes et al. 2010), and it is thought that the relationship between soil moisture and PCS is more complex than previously thought (Larkin et al. 2011). Hence, an alternative, reliable approach for suppressing PCS is needed.

Organic amendments are known to considerably influence soil microorganism community structures (Bernard et al. 2012; Cretoiu et al. 2013), and organic amendment is generally thought to affect the severity of soilborne diseases by changing the diversity and function of rhizosphere microbial communities (Singhai et al. 2011). Organic amendment reportedly enriches some bacterial groups that are antagonistic toward PCS pathogens, especially some Streptomyces populations (Bernard et al. 2012; Kinkel et al. 2012; Wiggins and Kinkel 2005). Noticeably, application of these antagonistic microbes, including species of Streptomyces (Hiltunen et al. 2009; Kobayashi et al. 2012; Liu et al. 1995), Bacillus (Han et al. 2005), and Pseudomonas (Singhai et al. 2011), has been shown to reduce the incidence of PCS under field conditions. In recent studies, inoculation with antagonists has been employed in conjunction with the application of organic amendments to improve PCS reduction efficiency (Kinkel et al. 2012; Larkin et al. 2011; Singhai et al. 2011).

In southwest Japan, mainly Kagoshima Prefecture, which is one of the largest cultivation areas for both rice and potato plants in Japan, amending soils with rice bran (RB), a byproduct of rice milling, has empirically been used to control PCS by local farmers. $\mathrm{RB}$ is thought to be primarily consumed by a wide range of 
microorganisms such as fungi and bacteria; therefore, $\mathrm{RB}$ amendment would be expected to considerably alter the microbial composition of a soil (Kanaiso and Yonemoto 2003; Yamagata and Ae 1999). However, the impact of RB amendment on a soil microbial community structure has not yet been assessed, and the scientific mechanism underlying disease suppression by RB amendment has not been elucidated.

In the present study, we first examined the effects of soil RB amendment on the population levels of Streptomyces spp. that cause PCS in the young tubers at the early tuber formation stage by quantitative polymerase chain reaction (qPCR) using $t x t A B$ genes, which are required for the production of the essential pathogenicity factor thaxtomin A (Loria et al. 2006; Nishi et al. 2015). Then, the bacterial community composition under RB amendment was characterized by amplicon sequencing of the $16 \mathrm{~S}$ ribosomal RNA (rRNA) gene in order to survey the bacterial groups that responded to RB amendment. To clarify the functionality of the soil microbial community under RB amendment, actinomycetes were isolated from a soil amended with RB, and their antagonistic activities against PCS pathogens were examined under various culture and field conditions.

\section{MATERIALS AND METHODS}

Bacterial strains and culture media. Three strains of PCS pathogens (S. scabiei strain S58, S. turgidiscabies strain T45, and S. acidiscabies a10) were isolated from diseased tubers in Kagoshima Prefecture, Japan, and used in this study (Nishi et al. 2015; Tomihama et al. 2016). Fresh RB was obtained from a local rice milling company in Kagoshima Prefecture. The chemical properties of the RB used in this study were analyzed by the Japan Food Research Laboratories (Tokyo) and a typical data set is shown in Supplementary Table S1. All chemicals were purchased from Nacalai Tesque (Kyoto, Japan) or Wako Chemicals (Osaka, Japan). The R2A, starch agar, and vermiculite-starch media, which were used for antimicrobial assays and for preparing a spore inoculum source, were prepared as described previously (Collins and Willoughby 1962; Matsumoto 1979; Nishi et al. 2015). The media $\mathrm{pH}$ were adjusted with 0.1 to $1 \mathrm{M}$ $\mathrm{NaOH}$ or $\mathrm{HCl}$ (unless otherwise stated in the text) using a $\mathrm{pH}$ spear tip electrode (F-21; Horiba Co., Kyoto, Japan) before autoclaving.

Field experimental design for assessing the disease suppression effect of RB amendment. Field experiments investigating the disease suppression effect of RB amendment on PCS were conducted in an experimental field at the Kagoshima Institute for Agricultural Development ( $31^{\circ} 28^{\prime} 56^{\prime \prime} \mathrm{N}, 130^{\circ} 20^{\prime} 34^{\prime \prime} \mathrm{E}, 25 \mathrm{~m}$ above sea level) in Kagoshima Prefecture, Japan, during the fall 2013 and 2014. The soil at the experimental site was classified as a volcanic ash soil (Andosol) with an initial $\mathrm{pH}\left(\mathrm{H}_{2} \mathrm{O}\right)$ of 5.86 in 2013 and 5.84 in 2014 (Supplementary Table S2). The field inoculum levels had been maintained since 1980 by artificial inoculation through the incorporation of tubers mainly infected by $S$. scabiei and S. turgidiscabies (Nishi et al. 2015).

In 2013, three different management approaches were included as factors: amendment, soil $\mathrm{pH}$, and fertilizer. The amendment factor consisted of either the presence (RB amendment) or absence of $\mathrm{RB}$ amendment (nonamendment). $\mathrm{RB}$ was applied at a rate of $3 \mathrm{t} / \mathrm{ha}$ in the furrow when the seed tubers were planted. The $\mathrm{pH}$ factor consisted of a soil $\mathrm{pH}$ of 5.8 (control, original soil with no $\mathrm{pH}$ adjustment) or 4.8. To adjust the soil $\mathrm{pH}$ from 5.8 to 4.8 , commercial-grade ferrous sulfate (Ferro-sand; Ishihara BioScience, Tokyo) was applied to the soil at a rate of $5 \mathrm{t} / \mathrm{ha} 12$ days before planting. Finally, two types of commercial fertilizers (conventional or slow-release nitrogen fertilizer) were applied at a rate of $1 \mathrm{t} / \mathrm{ha}(\mathrm{N}-\mathrm{P}-\mathrm{K}$ at 140:140: $140 \mathrm{~kg} / \mathrm{ha}$ ) at the time of planting. The research plots were established in a completely randomized design with two replication blocks for each treatment. There were 16 plots in total (two amendment levels $\times$ two $\mathrm{pH}$ levels $\times$ two fertilizer levels $\times$ two blocks) and the individual plots were $10 \mathrm{~m}$ long by $1 \mathrm{~m}$ wide. Potato seed tubers
('Nishiyutaka') treated with the fungicide fluazinam (Frowncide; Ishihara BioScience) were manually planted $20 \mathrm{~cm}$ apart (50 seed potatoes per plot) on 18 September 2013. No pesticide was applied over the growing season and the weeds were controlled manually.

In 2014, three different management approaches were included as factors: amendment, fertilizer, and calcium application. In this survey, diseased seed tubers (disease severity index score was 1 for these tubers, which had been collected during the previous growing season) were used to ensure high inoculum intensity during the experiment. The RB and fertilizer treatments were the same as described for the field experiment in 2013. The calcium factor consisted of either the presence or absence of a gypsum application, which was applied at a rate of $1 \mathrm{t} / \mathrm{ha}$ at the time of planting. The research plots had a completely randomized design with two replication blocks for each treatment. There were 16 plots in total (two amendment levels $\times$ two fertilizer levels $\times$ two calcium levels $\times$ two blocks) and the individual plots were $8 \mathrm{~m}$ long by $1 \mathrm{~m}$ wide. The potato seed tubers ('Nishiyutaka') were manually planted $20 \mathrm{~cm}$ apart (40 potatoes per plot) on 10 September 2014. No pesticide was applied over the growing season and manual weed control was carried out.

The experiments, which included the amendment factor, were repeated twice in 2015. The effects of lowering the soil $\mathrm{pH}$ (2013) and the gypsum application rate (2014) were not examined in the repeated experiments (Supplementary Table S3). Therefore, we have not mentioned the effect of these factors on disease incident in the main text.

Measurement of disease and yield parameters. Disease severity and the proportion of diseased tubers were measured at harvest (2 December 2013 and 29 November 2014). Individual tubers were scored in order to calculate the mean disease severity index at the plot level using the following formula: $\Sigma$ (disease index score $\times$ number of tubers $) /(5 \times$ total number of tubers $) \times 100$. The disease index score ( 0 to 5$)$ is the percentage of the surface area covered by scab lesions, where $0=$ no lesion and $0.5=$ up to $1,1=1$ to $3,2=3$ to $13,3=13$ to $25,4=25$ to 50 , and $5=$ over $50 \%$ covered. The total number and weight of tubers and the average weight of tubers per plant were recorded for each treatment plot. These data were then used to calculate the yield parameters.

Soil sampling, enumeration of microbial populations, and isolation of actinomycetes. In 2013, bulk soil samples for microbial enumeration and isolation were collected at three growth stages: the preplanting stage (16 September, 10 days after soil $\mathrm{pH}$ adjustment and 2 days before planting), the early tuber formation stage (18 October, approximately 4 weeks after planting), and the harvesting stage (22 December). Three soil cores ( $5 \mathrm{~cm}$ in diameter and $15 \mathrm{~cm}$ in depth) were taken from a position that was equidistant between plants in each plot and were pooled to form a composite sample for each plot. At the preplanting soil stage prior to the applications of RB and fertilizers, three soil cores were collected from each block. After sieving (2-mm mesh), each composite soil sample was divided into two subsamples for microbial enumeration and soil chemical analysis. After air drying, the soil samples were ground in a mortar and pestle and their general chemical characteristics, including soil $\mathrm{pH}$, were analyzed by Katakura Coop Agri Co., Ltd. (Tsuchiura, Japan).

Enumeration of total culturable bacteria and actinomycetes in the bulk soil was carried out using a plate counting method. Each soil subsample $(10 \mathrm{~g})$ was added to $40 \mathrm{ml}$ of sterile water and gently shaken at $200 \mathrm{rpm}$ for $1 \mathrm{~h}$ after ultrasonic treatment (SUW150; Sanyo, Tokyo) for $5 \mathrm{~min}$. Each soil suspension was serially diluted and $100 \mu \mathrm{l}$ of the diluent was spread onto two plates of R2A medium $(\mathrm{pH} 7.0)$. The plates were incubated at $25^{\circ} \mathrm{C}$ for 5 days in the dark. Then, the number of culturable actinomycetes in the bulk soil was measured by counting the number of actinomycete colonies (CFU/g of soil) on a plate based on their colony morphology. Subsequently, 96 isolates derived from the actinomycete colonies were collected from the bulk soils with and without RB amendment at the early 
tuber formation stage (18 October) (96 isolates were collected: 24 colonies $\times$ [nonamendment + conventional fertilizer] $\times$ two blocks and 24 colonies $\times$ [RB amendment + conventional fertilizer] $\times$ two blocks).

Bulk soil samples for culturable actinomycete enumeration in 2014 were collected only at the early tuber formation stage (6 October). Two soil cores were taken from a position that was equidistant between two plants in each plot and were pooled to form a composite sample representing each plot. The number of total culturable actinomycetes in each composite sample was assessed using the plate counting method described above. In addition, 240 bacterial colonies (including actinomycetes) were collected from the fertilized bulk soil with and without RB amendment at the early tuber formation stage ( 240 isolates in total: 60 colonies $\times$ [nonamendment + conventional fertilizer + no gypsum application $] \times$ two blocks and 60 colonies $\times[\mathrm{RB}$ amendment + conventional fertilizer + no gypsum application] $\times$ two blocks).

In both 2013 and 2014, the colonies were randomly isolated and purified twice by single-colony isolation, and a piece of each colony (mycelial mat) was stored in $10 \%$ glycerol stock at $-30^{\circ} \mathrm{C}$ for further investigation.

Soil and tuber DNA extraction. Following the method used in the field experiment, rhizosphere soil samples for amplicon sequencing were taken from the soil adhering to the roots of three potato plants in each of eight selected plots on 6 November 2013 at the early tuber formation stage ( 24 samples in total: two amendment levels $\times$ two fertilizer levels $\times$ intact soil at pH $5.8 \times$ two blocks $\times$ three potato plant replicates). The potato roots were gently shaken to remove loosely adhered soil, and the rhizosphere soil was collected by vigorously shaking the roots in a polyvinyl propylene bag. DNA was extracted from $500 \mathrm{mg}$ of the rhizosphere soil sample using a FastDNA SPIN Kit for Soil (MP Biomedicals, Solon, $\mathrm{OH}$ ).

In the 2014 field experiment, rhizosphere soil samples and young tuber samples (approximately 5 to $10 \mathrm{~mm}$ in diameter) were taken in each plot on 6 October from two potato plants at the early tuber formation stage for amplicon sequencing and qPCR (32 samples in total: two amendment levels $\times$ two fertilizer levels $\times$ two calcium levels $\times$ two blocks $\times$ two potato plant replicates). The rhizosphere soil samples were collected as described above, and DNA was extracted from $500 \mathrm{mg}$ of rhizosphere soil or $100 \mathrm{mg}$ of young tuber surface using an ISOIL kit (Nippon Gene, Tokyo) and a Quantum Prep Kit (Bio-Rad Laboratories, Hercules, CA), respectively (Tanaka and Ikeda 2002).

Following the extraction, the quality and quantity of the extracted DNA samples were assessed by agarose gel electrophoresis and spectrophotometry (ND-1000; NanoDrop Technology, Wilmington, DE).

Quantification of the pathogenic Streptomyces spp. Quantification of the pathogenic Streptomyces spp. in the 2014 potato tuber DNA samples was carried out by qPCR using the $t x t A B$ operon, as previously reported (Nishi et al. 2015; Qu et al. 2008). Briefly, primer pairs StrepF (5'-GCAGGACGCTCACCAGG TAGT-3') and StrepR ( $5^{\prime}$-ACTTCGACACCGTTGTCCTCAA-3') were used in an SYBR Green real-time PCR assay. Real-time PCR amplifications were performed in $25-\mu l$ reaction mixtures containing $1 \times$ DimerEraser master mix (TaKaRa Co., Ltd., Kusatsu, Shiga, Japan) and $0.3 \mu \mathrm{M}$ each primer. Tuber DNA extract ( $3 \mu \mathrm{l})$ was used as the DNA template per reaction. Real-time PCR amplifications were carried out on an Applied Biosystems 7300 Real-Time PCR System (Applied Biosystems, Foster City, CA), with an initial activation step of $95^{\circ} \mathrm{C}$ for $10 \mathrm{~s}$ followed by 45 cycles of $95^{\circ} \mathrm{C}$ for $5 \mathrm{~s}$, $55^{\circ} \mathrm{C}$ for $10 \mathrm{~s}$, and $72^{\circ} \mathrm{C}$ for $35 \mathrm{~s}$. Serial dilutions of genomic DNA from pathogenic S. scabiei S58 were used as the standard. Quantifications of the pathogenic Streptomyces spp. in young tubers were repeated twice in 2015 and gave similar results (Supplementary File S1; Supplementary Table S4).

16S rRNA gene amplicon sequencing, sequence editing, and community analyses. In 2013, amplicon sequencing and amplification of the V4 region of the $16 \mathrm{~S}$ rRNA gene using primers
515F and 806R (Caporaso et al. 2012) were performed using the paired-end Illumina MiSeq at FASMAC Co., Ltd. (Atugi, Japan). Sequence data editing was carried out as described in a previous study (Narihiro et al. 2014). Briefly, raw 16S rRNA gene sequences were processed using QIIME 1.8.0 (Caporaso et al. 2010). Lowquality sequences shorter than $300 \mathrm{bp}$, with an average quality score lower than 25 or with ambiguous bases, or mismatching primer sequences were eliminated from downstream analyses. The filtered and denoised sequence data were grouped into operational taxonomic units (OTU) by using the pick_denovo_otus command with default parameters (furthest neighbor). The sequences with $\geq 97 \%$ identities were grouped into one OTU by the UCLUST algorithm (Edgar 2010), and then the representative sequences of each OTU were aligned using PyNAST (Narihiro et al. 2014). The taxonomic assignment of each OTU was performed by an RDP classifier trained using a dataset from Greengenes v.13.8 at a minimum confidence level of 0.8 (Wang and Qian 2009). The sequence data were compared with the $16 \mathrm{~S}$ rRNA genes in the RDP release 10 database using the BLAST+ program (Cole et al. 2009). After taxonomic assignment, $\alpha$ diversity indices (Chaol and Shannon) for the 16S rRNA genes libraries and the weighted UniFrac distances were calculated and used for principal coordinates analysis (PCoA) by the QIIME pipeline (Caporaso et al. 2010). The $\alpha$ diversity and relative abundance were calculated from subsampled data (36,463 reads per sample), such that all samples had an equal sampling effort. An average relative abundance and diversity index was calculated for the three potato replicates in each plot. We used a two-way analysis of variance (ANOVA) to fit the linear models in JMP ver. 12 (SAS Institute, Tokyo). This included both amendment and fertilizer factors as fixed effects and the block factor as a random effect.

Amplification of the V4 region of the 16S rRNA gene using primers 515F and 806R (Caporaso et al. 2012) and amplicon sequencing and editing in 2014 were performed using the Roche GS junior at the RIKEN BioResource Center (Tsukuba, Japan) and followed Roche technical bulletins 2009-005 (April 2009) and 2011-007 (January 2012). The sequence data were denoised and the low-quality sequences, pyrosequencing errors, and chimeras were removed. Then, the sequences were clustered into OTU at $97 \%$ identity using QIIME 1.8.0, as described above. The $\alpha$ diversity and relative abundance were calculated from subsampled data $(1,983$ reads per sample), such that all samples represented an equal sampling effort. For relative abundance and diversity statistical analyses, the average relative abundance and diversity index of two potato replicates in each plot were taken as a single plot-level mean. We used a three-way ANOVA to fit the models in JMP ver. 12 (SAS Institute). This included amendment, fertilizer, and calcium factors as fixed effects and the block factor as a random effect.

Assessment of the antagonistic potentials of actinomycete isolates against PCS pathogens. To assess the antagonistic activity of the 96 actinomycetes isolated in 2013 against PCS pathogens, two strains of pathogenic Streptomyces spp. (S. scabiei S58 and S. turgidiscabies T45) and the 96 actinomycete isolates were grown on starch agar plates $(\mathrm{pH} 7.0)$ at $25^{\circ} \mathrm{C}$ for 10 days in the dark. Spore suspensions were then made by scraping the mycelium with a sterile loop and mixing the loop with $1 \mathrm{ml}$ of sterile water to detach the spores from the mycelium. Spore suspension at approximately $10^{5} \mathrm{CFU} / \mathrm{ml}$ was prepared for each strain and isolate. To assess the antagonistic activity of actinomycete isolates under two different $\mathrm{pH}$ conditions ( $\mathrm{pH} 7.0$ and 5.0), a 500- $\mu$ l spore suspension of a pathogenic Streptomyces bacterium was spread on an R2A plate that was adjusted to either $\mathrm{pH} 7.0$ or 5.0 to act as an indicator. Then, a 10- $\mu$ l spore suspension of an actinomycete isolate was dropped onto a plate (4 drops/plate). The inoculated R2A plates were incubated at $25^{\circ} \mathrm{C}$ in the dark for 3 days ( $\mathrm{pH}$ 7.0) or 6 days ( $\mathrm{pH}$ 5.0). Antagonistic activity (including competitive and antibiotic interactions) was evaluated by the presence of a clear zone around an actinomycete isolate. The proportion of the actinomycete isolates producing a clear zone of inhibition was calculated for the total 
number of isolates derived from the bulk soil with or without RB amendment. The radius of each clear zone was used as an indicator of the growth inhibitory activity. The experiments were repeated twice and gave similar results.

Phylogenetic distribution analyses of actinomycete isolates by $16 \mathrm{~S}$ rRNA gene sequences. The genomic DNA of the isolates and pathogenic Streptomyces spp. was extracted from a piece of colony grown on an R2A plate at $25^{\circ} \mathrm{C}$ in the dark for 5 days using a PrepMan Ultra Reagent (Applied Biosystems, Warrington, UK). Amplification of the 16S rRNA gene was performed using universal primers $27 \mathrm{~F}$ (5'-AGAGTTTGATCMTGGCTCAG- $3^{\prime}$ ) and $1525 \mathrm{R}$ (5'-AAGGAGGTGWTCCARCC-3'), as previously described (Ikeda et al. 2011), and sequencing analyses were performed at TaKaRa Co., Ltd. In total, 140 actinomycete sequences (73 sequences in 2013 and 67 sequences in 2014) and sequences from three strains of pathogenic Streptomyces spp. were obtained. These sequences were assigned by MOTHUR into OTU using a cutoff of 0.01 ( $\geq 99 \%$ identity) for the distance matrix, as described previously (Ikeda et al. 2011). BLASTN was used to classify the OTU and to identify their closest relatives in the GenBank database. During the phylogenetic analyses, their sequences were aligned by CLUSTALW, and the neighbor-joining method was used to build a phylogenetic tree. The PHYLIP format tree output was obtained and 1,000 bootstrap trials were carried out. The trees were constructed using MEGA6 software (Tamura et al. 2013). Statistical differences in the number of isolates belonging to each OTU were evaluated between the nonamendment and RB-amendment treatments for 2013 and 2014 by using the compare algorithm in RDP. The $P$ value was estimated from the $\mathrm{Z}$ critical value (Wang et al. 2007).

PCS suppression after inoculation with Streptomyces isolates under field conditions. A field experiment to assess the ability of Streptomyces isolates to suppress PCS was carried out in 2014 using "the bottomless frame method" (Sakamoto et al. 2011). Two different management approaches were included as factors: biocontrol treatments and RB amendment. The biocontrol treatment factor consisted of a pathogen inoculation (S. scabiei S58) without a Streptomyces isolate (positive control) and a dual inoculation of a pathogen and one of four Streptomyces isolates. The four candidate biocontrol agents isolated from RB-amended soil (ANA105, ANA109, ANA1007, and ANA1906) were selected after phylogenetic analyses of Streptomyces isolates for representing a wide phylogenetic diversity range. The four Streptomyces isolates and the pathogenic $S$. scabiei $\mathrm{S} 58$ were cultured on $1 \mathrm{~kg}$ of vermiculitestarch medium at $25^{\circ} \mathrm{C}$ for 20 days. Inoculum at approximately $10^{7}$ $\mathrm{CFU} / \mathrm{g}$ was prepared for each isolate and pathogen. A proportion of each inoculum source (20 g for strain S58 and $80 \mathrm{~g}$ for each Streptomyces isolate) was mixed, and this mixture was gently blended with $1 \mathrm{~kg}$ of soil and poured into a bottomless frame $(32 \mathrm{~cm}$ in diameter and $30 \mathrm{~cm}$ in depth; $0.08 \mathrm{~m}^{2}$ ) in a field. The amendment factor consisted of nonamendment and RB amendment. The RB was applied at a rate of $24 \mathrm{~g} /$ frame (equivalent to $3 \mathrm{t} / \mathrm{ha}$ ). The biocontrol and amendment treatments were applied just before planting (15 October 2014). In total, 40 framed, $0.08-\mathrm{m}^{2}$ plots (two amendment levels $\times$ five biocontrol levels $\times$ four replicates) were established with a completely randomized design. One healthy potato seed tuber (Nishiyutaka) per frame was manually planted in the frame soil on 15 October 2014. No pesticide was applied over the growing season, and manual weed control was carried out. Disease severity and the proportion of diseased tubers were measured at the harvesting stage (24 December 2014), as described above. The experiments, which included the soil amendment factor, were repeated in spring 2015 and gave similar results.

Statistics. Experimental designs fitting linear model analysis (one-way, two-way, and three-way ANOVA), a linear regression analyses, Spearman's rank correlation, stepwise regression of factors, and calculation of false discovery rate (FDR) $P$ values (Benjamini and Hochberg 1995) were performed using JMP ver. 12.0 (SAS Institute). For statistical comparisons, we conducted a fitting linear models analysis that included all factors as the main effects; however, the interactions between factors were not included in the analysis. Disease severity data were arcsine transformed, and the actinomycete population and the pathogenic Streptomyces data were $\log$ transformed. For the responses that were shown to be significantly different by the models, a Student's $t$ test or a Wilcoxon signed test was performed to compare between levels at $\alpha=0.05$.

Nucleotide sequence accession numbers. Sequence data from amplicon sequencing in 2013 were made publicly available at the DNA Data Bank of Japan (DDBJ) Sequence Read Archive under accession number DRA003981, BioProject (PRJDB3924), and BioSample (SAMD00031517-SAMD00031540). Sequence data from amplicon sequencing in 2014 were made publicly available at the DDBJ Sequence Read Archive under accession number DRA004010, BioProject (PRJDB3924), and BioSample (SAMD00041214-SAMD00041245). The sequences of the actinomycete isolates used in phylogenetic analyses have been deposited in DDBJ under accession numbers LC061295-LC061437.

\section{RESULTS}

RB amendment reduced the occurrence of common scab. The suppressive effect of RB amendment against PCS was confirmed in field experiments conducted over two consecutive years (2013 and 2014) (Table 1). In 2013, the RB amendment significantly reduced PCS disease severity compared with the nonamendment control (Table 1). Similarly, in 2014, RB amendment again significantly reduced PCS (Table 1). The fertilizer factor had

TABLE 1. Effect of rice bran amendment on the severity of potato common scab, the actinomycete population, and the amount of pathogenic Streptomyces bacteria in young tubers after the field experiments in 2013 and $2014^{\mathrm{w}}$

\begin{tabular}{|c|c|c|c|c|c|}
\hline Year & Factor $^{\mathrm{x}}$ & Level & Disease severity ${ }^{y}$ & Actinomycetes $(\log \mathrm{CFU} / \mathrm{g} \text { of soil) })^{\mathrm{y}}$ & Pathogenic Streptomyces (log fg/g of tuber $)^{\mathrm{z}}$ \\
\hline \multirow[t]{3}{*}{2013} & Amendment & Nonamendment & $12.4 \pm 7.3 \mathrm{a}$ & $5.9 \pm 0.2 b$ & NT \\
\hline & & Rice bran amendment & $4.1 \pm 3.2 \mathrm{~b}$ & $7.2 \pm 0.1 \mathrm{a}$ & NT \\
\hline & $P$ value & & 0.011 & $<0.001$ & \\
\hline & & Rice bran amendment & $15.9 \pm 7.2 \mathrm{~b}$ & $7.8 \pm 0.3 \mathrm{a}$ & $4.4 \pm 0.8 b$ \\
\hline & $P$ value & & $<0.001$ & $<0.001$ & 0.002 \\
\hline
\end{tabular}

${ }^{\mathrm{w}}$ Lowercase letters represent significant differences within columns at $\alpha=0.05$ and NT indicates not tested.

${ }^{x}$ Factors other than amendment (fertilization in 2013 and 2014, pH treatment in 2013, and gypsum application in 2014) are shown in Supplementary Table S3.

y Disease severity at harvesting and the actinomycete population at the early tuber formation stage are shown. Values are the least square means $( \pm$ standard deviation) for each level by three-way analysis of variance (ANOVA) in $2013(n=8)$ and $2014(n=8)$. Student's $t$ test was used for further comparison when the ANOVA showed significant differences between levels $(P<0.05)$. Disease severity and actinomycete population data were arcsine and log transformed, respectively.

z Amount of pathogenic Streptomyces bacteria (log transformed) in young tubers at the early tuber formation stage was examined by qPCR analysis and the values are the least square means ( \pm standard deviation) for each level by three-way ANOVA in $2014(n=8)$. A Wilcoxon signed test was used for further comparison when the ANOVA showed significant differences between levels $(P<0.05)$. 
no effect on the incidence of PCS in both years. In 2014, the amounts of pathogenic Streptomyces bacteria in the young tubers were reduced by the RB amendment compared with the nonamendment control (Table 1). The declines in disease severity and the pathogenic Streptomyces population in young tubers after RB amendment were also confirmed in 2015.

The correlation analyses indicated that, in 2014, there was a significant positive correlation between the amount of pathogenic Streptomyces bacteria in young tubers and disease severity but a negative correlation between actinomycete population and disease severity (Supplementary Fig. S2A and B). In addition, stepwise screening of factors that correlated with disease severity in the experiment conducted in 2014 indicated that disease severity was significantly estimated by two factors: the amount of pathogenic Streptomyces bacteria in the tuber and the actinomycete population (Supplementary Fig. S2C).

Impact of $\mathrm{RB}$ amendment on microbial composition in the rhizosphere. Bacterial community analyses of the potato rhizosphere by amplicon sequencing in 2013 revealed that the RB amendment significantly increased the relative abundance of grampositive bacteria. The $\alpha$ diversity analysis indicated that the number of OTU and the diversity indexes, such as the Chao1 and Shannon indexes, were significantly reduced by RB amendment in both 2013 and 2014 (Supplementary Table S5). Other factors such as fertilization had no effect on the $\alpha$ diversity of the rhizosphere bacterial community. Weighted UniFrac PCoA analysis showed that nonamended rhizosphere soil samples formed a tight cluster (Fig. 1A). They were distinctly separated from RB-amended samples along PC1 (64.6\%), and variability was high among the RBamended samples in 2013 (Fig. 1A).

Analysis of relative abundances in 2013 indicated that, at the phylum level, the most abundant phyla in the nonamendment soil were Proteobacteria, followed by Acidobacteria, Actinobacteria, and Firmicutes (Table 2). These four phyla accounted for $73.1 \%$ of the total reads (Table 2). RB amendment exclusively increased the relative abundance of Actinobacteria but decreased the relative abundance of Acidobacteria compared with the nonamendment soil (Table 2). At the order level, the relative abundances for Actinomycetales and Saprospirales were significantly increased by RB amendment (Table 2). In contrast, Acidobacteriales, Gaiellales, and Solibacteriales were significantly reduced by RB amendment in 2013 (Table 2). Accordingly, at the genus level, the relative abundances of genera Bacillus, Streptomyces, Chitinophaga, and Actinomadura significantly increased, whereas unclassified Koribacteraceae and unclassified Gaiellaceae were significantly reduced after RB amendment in 2013 (Table 3). There was a power law relationship between the magnitude of increase by $\mathrm{RB}$ amendment (ratio of RB amendment to nonamendment relative to abundance at the genus level) and the number of genera at each magnitude (Supplementary Fig. S3A). With the exception of amendment, other factors such as fertilization had no effect on the rhizosphere bacterial community (Supplementary Tables S6 to S8). A similar trend for rhizosphere bacterial community shifts after RB amendment was also confirmed in 2014 (Supplementary Tables S9 and S10; Supplementary Figs. S3B and S4).

The Spearman's rank correlation analyses indicated that the relative abundance of Streptomyces spp. was most negatively correlated with disease severity in 2014 (Table 4). In addition, OTU 1 (closest relative species: S. avellaneus, 100\% identity) and OTU 2 (closest relative species: $S$. diastaticus, $100 \%$ identity), which were the two most abundant Streptomyces OTU out of the 296 identified in 2013, had significantly increased following RB amendment (Fig. 1B). However, not all Streptomyces OTU were significantly changed by RB amendment (Fig. 1B), which suggested that RB amendment differentially affected the populations of certain groups of Streptomyces spp. in the potato rhizosphere.

Antagonistic activities of actinomycetes against pathogenic Streptomyces spp. The increase in soil actinomycetes, including the genus Streptomyces, in the bulk soil amended with RB was also confirmed by colony counting. In the 2013 experiment, the actinomycete population significantly increased after RB amendment by up to $10^{7} \mathrm{CFU} / \mathrm{g}$ of soil at the early tuber formation stage (Table 1), and this was maintained at a similar level until the harvesting stage (data not shown). A similar result was obtained in the 2014 experiment (Table 1). However, fertilization had no effect on the cultural population of soil actinomycetes.

The PCS pathogens belong to the genus Streptomyces. Therefore, we isolated and characterized the soil actinomycetes, including Streptomyces spp., from nonamended soil and from RB-amended soil. More than $80 \%$ of the actinomycete isolates in 2013 produced an inhibitory zone on the R2A medium plate against both $S$. scabiei S58 and S. turgidiscabies T45 (Fig. 2A). The average diameter of the inhibitory zone on the $\mathrm{pH} 5.0$ medium was significantly greater than on the $\mathrm{pH} 7.0$ medium (Fig. 2A and B). The diameters of the
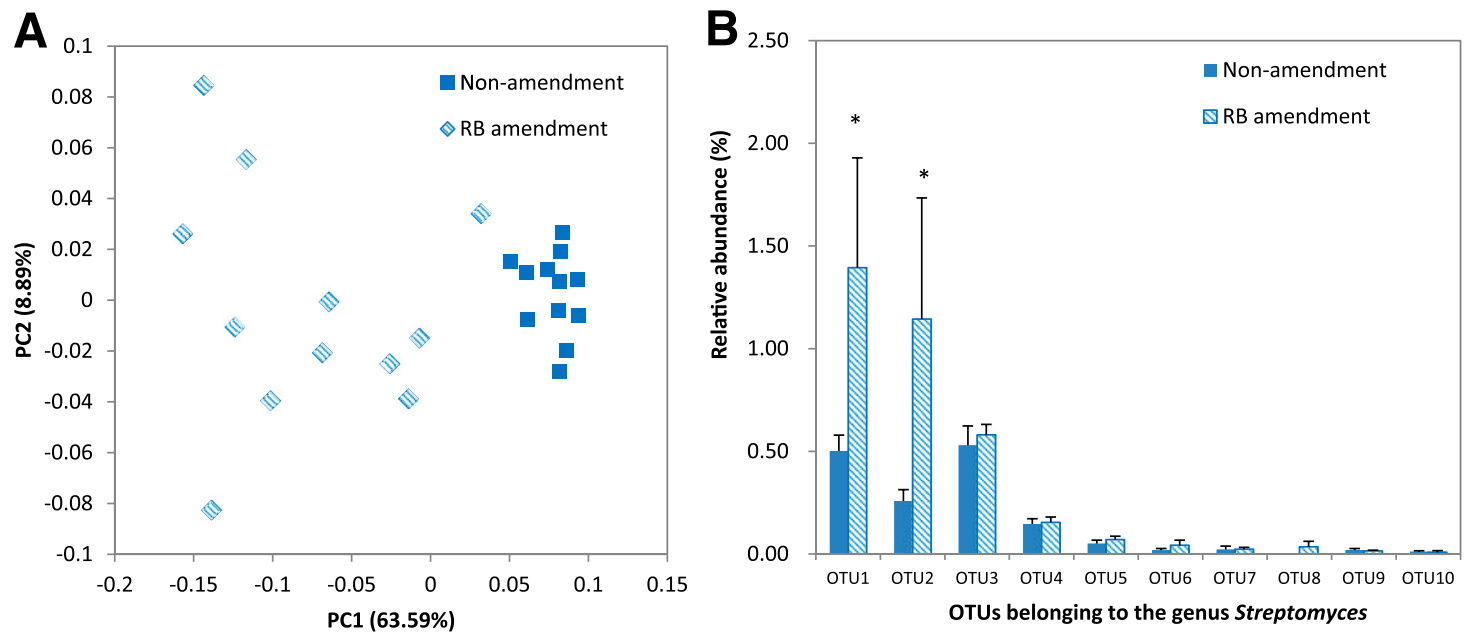

Fig. 1. Bacterial composition changes in the potato rhizosphere caused by rice bran (RB) amendment in 2013. A, Principal coordinates analysis of bacterial communities in the potato rhizosphere. Bacterial communities in potato rhizospheres were analyzed based on weighted UniFrac distance matrixes in 2013. Solid squares and open squares indicate samples from nonamended and RB-amended rhizospheres, respectively. B, Changes in the relative abundances of Streptomyces operational taxonomic units (OTU) (dominant 10 of 296 OTU belong to Streptomyces spp.). Relative abundance of OTU 1 and 2 were significantly increased by RB amendment. Not all OTU belonging to Streptomyces spp. responded in a similar way to RB amendment. When OTU were significantly different according to the analysis of variance (false discovery rate [FDR] $P<0.05$ ), a Wilcoxon signed test was performed to compare the nonamendment and RB-amendment treatments. Asterisks represent significant differences for each OTU at $\alpha=0.05$. Columns and error bars indicate the least square means and standard deviation $(n=4)$, respectively. 
inhibitory zones of isolates from the nonamended soil were slightly but significantly greater than those from the RB-amended soil. However, there was no significant difference among the average diameters of the inhibitory zones against $S$. scabiei S58 and S. turgidiscabies T45 (Fig. 2B). These data clearly suggest that most of the indigenous actinomycetes have antagonistic activity against S. scabiei S58 and $S$. turgidiscabies T45, especially under low $\mathrm{pH}$ conditions. More importantly, RB amendment increased the populations of the indigenous actinomycetes that were antagonistic to PCS pathogens.

Phylogenetic distribution analyses of actinomycete isolates. The 16S rRNA gene sequences from a total of 140 actinomycete isolates were assigned to 39 OTU with $\geq 99 \%$ identity (Fig. 3). Most of the OTU were classified into the genus Streptomyces (92.2\%), and cluster analyses identified two abundant OTU (OTU ANA109 and OTU ANA105) (Fig. 3). The cluster analyses revealed that RB amendment increased the number of isolates belonging to OTU ANA109 (closest relative species: S. glaucescens, 99\% identity) and OTU ANA105 (closest relative species: S. roseochromogenus, 99\% identity) but decreased the number of isolates in OTU ANA2110 (closest relative species: S. flavidovirens, 99\% identity) (Fig. 3).

Suppression of PCS after inoculation with antagonistic Streptomyces isolates under field conditions. The RB amendment significantly reduced the incidence of PCS compared with the nonamendment control (two-way ANOVA, $P<0.001$ ) (Fig. 4). Under the nonamendment condition, inoculation with isolates ANA1906 or ANA109 significantly reduced disease severity compared with the noninoculated control (Fig. 4). Furthermore, inoculation with isolate ANA105 or ANA1906 significantly reduced

TABLE 2. Relative abundance of phyla or orders responding to rice bran amendment of the potato rhizosphere after the field experiment in 2013

\begin{tabular}{|c|c|c|c|c|}
\hline \multirow[b]{2}{*}{ Taxon $^{\mathrm{x}}$} & \multicolumn{2}{|c|}{ Relative abundance $(\%)^{\mathrm{w}}$} & \multirow[b]{2}{*}{$\mathrm{R} / \mathrm{N}^{\mathrm{y}}$} & \multirow{2}{*}{$\begin{array}{c}\mathrm{FDR}^{\mathrm{z}} \\
P \text { value }\end{array}$} \\
\hline & Nonamendment & RB amendment & & \\
\hline \multicolumn{5}{|l|}{ Phylum } \\
\hline Proteobacteria & $33.22 \pm 0.80$ & $30.49 \pm 2.25$ & 0.92 & 0.411 \\
\hline Acidobacteria & $15.68 \pm 0.40 \mathrm{a}$ & $10.47 \pm 0.43 b$ & 0.67 & $<0.001$ \\
\hline Actinobacteria & $13.66 \pm 0.10 b$ & $20.18 \pm 0.21 \mathrm{a}$ & 1.48 & 0.004 \\
\hline Firmicutes & $10.54 \pm 0.89$ & $16.33 \pm 3.73$ & 1.55 & 0.086 \\
\hline Chloroflexi & $6.83 \pm 0.29 a$ & $4.99 \pm 0.57 b$ & 0.73 & 0.008 \\
\hline Gemmatimonadetes & $6.59 \pm 0.79$ & $5.13 \pm 1.13$ & 0.78 & 0.299 \\
\hline Bacteroidetes & $3.66 \pm 0.30$ & $5.11 \pm 0.95$ & 1.40 & 0.063 \\
\hline Verrucomicrobia & $2.58 \pm 0.36$ & $1.83 \pm 0.32$ & 0.71 & 0.121 \\
\hline Planctomycetes & $2.05 \pm 0.07$ & $1.57 \pm 0.23$ & 0.77 & 0.042 \\
\hline Nitrospira & $1.86 \pm 0.37$ & $1.18 \pm 0.15$ & 0.63 & 0.077 \\
\hline Armatimonadetes & $0.79 \pm 0.09 \mathrm{a}$ & $0.48 \pm 0.01 \mathrm{~b}$ & 0.61 & 0.004 \\
\hline WS3 & $0.70 \pm 0.12 \mathrm{a}$ & $0.51 \pm 0.06 \mathrm{~b}$ & 0.73 & 0.017 \\
\hline \multicolumn{5}{|l|}{ Order } \\
\hline Bacillales & $9.32 \pm 0.92$ & $15.66 \pm 3.77$ & 1.68 & 0.070 \\
\hline Rhizobiales & $7.32 \pm 0.62$ & $7.80 \pm 1.50$ & 1.07 & 0.227 \\
\hline Actinomycetales & $7.12 \pm 0.62 b$ & $15.20 \pm 1.86 \mathrm{a}$ & 2.13 & $<0.001$ \\
\hline Acidobacteriales & $6.08 \pm 0.44 \mathrm{a}$ & $3.87 \pm 0.19 b$ & 0.64 & $<0.001$ \\
\hline Burkholderiales & $5.83 \pm 1.19$ & $4.88 \pm 0.50$ & 0.84 & 0.505 \\
\hline Gaiellales & $3.81 \pm 0.46 \mathrm{a}$ & $2.69 \pm 0.25 b$ & 0.71 & 0.012 \\
\hline Xanthomonadales & $3.73 \pm 0.24$ & $5.19 \pm 0.14$ & 1.39 & 0.181 \\
\hline Saprospirales & $3.10 \pm 0.25 b$ & $4.94 \pm 0.84 \mathrm{a}$ & 1.59 & 0.044 \\
\hline Myxococcales & $2.65 \pm 0.15$ & $2.54 \pm 0.10$ & 0.96 & 0.681 \\
\hline Solibacterales & $2.42 \pm 0.21 \mathrm{a}$ & $1.76 \pm 0.20 \mathrm{~b}$ & 0.73 & 0.004 \\
\hline Sphingomonadales & $2.13 \pm 0.30$ & $2.03 \pm 0.21$ & 0.95 & 0.502 \\
\hline iii1-15 & $2.34 \pm 0.30 \mathrm{a}$ & $1.76 \pm 0.11 b$ & 0.75 & 0.018 \\
\hline Rhodospirillales & $1.84 \pm 0.25$ & $1.74 \pm 0.16$ & 0.95 & 0.521 \\
\hline Nitrospirales & $1.86 \pm 0.37$ & $1.18 \pm 0.15$ & 0.63 & 0.077 \\
\hline
\end{tabular}

w Values are the least square means ( \pm standard deviation) for each level of the amendment factor obtained by two-way analysis of variance (ANOVA) in 2013 ( $n=4)$. A Wilcoxon signed test was used to compare nonamendment and rice bran $(\mathrm{RB})$ amendment data when the ANOVA showed significant differences between taxa (FDR $P<0.05$ ). Letters represent significant differences at $\alpha=0.05$. Relative abundances of phyla or orders responding to fertilization is shown in Supplementary Table S6.

x Dominant 12 phyla and 14 orders are shown.

${ }^{y}$ Ratio of RB amendment to nonamendment relative abundance.

z False discovery rate. disease severity after $\mathrm{RB}$ amendment compared with the noninoculated control (Fig. 4).

\section{DISCUSSION}

There have been previous reports on the suppressive effects of organic amendments on PCS (Bonanomi et al. 2010; Larkin 2008; Lazarovits 2001; Wiggins and Kinkel 2005). However, such effects

TABLE 3. Relative abundance of genera responding to rice bran (RB) amendment of the potato rhizosphere after the field experiment in 2013

\begin{tabular}{|c|c|c|c|c|}
\hline \multirow[b]{2}{*}{ Genus $^{\mathrm{y}}$} & \multicolumn{2}{|c|}{ Relative abundance $(\%)^{\mathrm{x}}$} & \multirow[b]{2}{*}{$\mathrm{R} / \mathrm{N}^{\mathrm{z}}$} & \multirow[b]{2}{*}{$\begin{array}{c}\text { FDR } \\
P \text { value }\end{array}$} \\
\hline & Nonamendment & $\begin{array}{c}\text { RB } \\
\text { amendment }\end{array}$ & & \\
\hline Bacillus & $5.34 \pm 0.49 b$ & $12.48 \pm 3.26 \mathrm{a}$ & 2.34 & 0.026 \\
\hline Uc Koribacteraceae & $3.84 \pm 0.15 \mathrm{a}$ & $2.46 \pm 0.23 b$ & 0.64 & $<0.001$ \\
\hline Burkholderia & $3.60 \pm 1.25$ & $2.54 \pm 0.49$ & 0.71 & 0.210 \\
\hline Uc Gaiellaceae & $3.45 \pm 0.37 \mathrm{a}$ & $2.40 \pm 0.19 \mathrm{~b}$ & 0.70 & 0.007 \\
\hline Streptomyces & $1.65 \pm 0.18 b$ & $3.58 \pm 0.52 \mathrm{a}$ & 2.17 & 0.008 \\
\hline Uc Gemmatimonadetes & $2.81 \pm 0.48$ & $2.16 \pm 0.47$ & 0.77 & 0.283 \\
\hline Uc Chitinophagacea & $2.13 \pm 0.12$ & $2.63 \pm 0.39$ & 1.23 & 0.102 \\
\hline Rhodoplane & $2.64 \pm 0.29 \mathrm{a}$ & $1.73 \pm 0.15 b$ & 0.66 & 0.002 \\
\hline Uc iii 1-15 & $2.18 \pm 0.29 \mathrm{a}$ & $1.64 \pm 0.09 b$ & 0.75 & 0.017 \\
\hline Uc Myxococcales & $1.60 \pm 0.08$ & $1.68 \pm 0.11$ & 1.05 & 0.414 \\
\hline Uc Bradyrhizobiaceae & $1.63 \pm 0.13$ & $1.47 \pm 0.36$ & 0.90 & 0.380 \\
\hline Kaistobacter & $1.57 \pm 0.25$ & $1.48 \pm 0.15$ & 0.94 & 0.393 \\
\hline Paenibacillus & $1.49 \pm 0.09$ & $1.37 \pm 0.19$ & 0.92 & 0.668 \\
\hline Uc Rhodospirillaceae & $1.57 \pm 0.22$ & $1.27 \pm 0.04$ & 0.81 & 0.177 \\
\hline Rhodanobacter & $1.03 \pm 0.06$ & $1.75 \pm 1.42$ & 1.70 & 0.351 \\
\hline Ca. Koribacter & $1.64 \pm 0.20 \mathrm{a}$ & $0.98 \pm 0.19 b$ & 0.60 & 0.031 \\
\hline Uc Sinobacteraceae & $1.44 \pm 0.21$ & $1.14 \pm 0.10$ & 0.79 & 0.177 \\
\hline Uc Xanthomonadaceae & $0.84 \pm 0.16$ & $1.40 \pm 0.28$ & 1.67 & 0.021 \\
\hline Uc Solibacterales & $1.31 \pm 0.13 \mathrm{a}$ & $0.92 \pm 0.16 b$ & 0.70 & 0.018 \\
\hline Uc Gemmatimonadetes & $1.06 \pm 0.44$ & $1.17 \pm 0.34$ & 1.10 & 0.997 \\
\hline Uc Gemmatimonadetes & $1.43 \pm 0.27 \mathrm{a}$ & $0.74 \pm 0.14 b$ & 0.52 & 0.015 \\
\hline Chitinophaga & $0.34 \pm 0.14 b$ & $1.80 \pm 0.52 \mathrm{a}$ & 5.29 & 0.018 \\
\hline Uc Micrococcaceae & $0.87 \pm 0.06$ & $1.19 \pm 0.43$ & 1.37 & 0.221 \\
\hline Uc Syntrophobacteraceae & $1.27 \pm 0.13 \mathrm{a}$ & $0.79 \pm 0.11 b$ & 0.62 & 0.021 \\
\hline Uc MND1 & $1.20 \pm 0.09 \mathrm{a}$ & $0.83 \pm 0.02 \mathrm{~b}$ & 0.69 & 0.005 \\
\hline Actinomodura & $0.16 \pm 0.05 b$ & $1.69 \pm 0.34 \mathrm{a}$ & 10.56 & 0.002 \\
\hline Nitrospira & $1.06 \pm 0.22$ & $0.62 \pm 0.08$ & 0.58 & 0.057 \\
\hline
\end{tabular}

$\mathrm{x}$ Values are the least square means ( \pm standard deviation) for each level of the amendment factor obtained by two-way analysis of variance (ANOVA) in $2013(n=4)$. A Wilcoxon signed test was performed to compare relative abundance between nonamendment and RB amendment when the ANOVA showed significant differences between taxa (FDR $P<0.05$ ). Letters represent significant differences at $\alpha=0.05$. Relative abundances of genera responding to fertilization are shown in Supplementary Table S7.

y In all, 27 dominant genera are shown. Uc = unclassified. Unclassified taxa were based on the highest taxonomic level of resolution.

$\mathrm{z}$ Ratio of $\mathrm{RB}$ amendment to nonamendment relative abundance.

TABLE 4. Dominant 10 taxa that showed negative correlations for disease severity or the amount of pathogenic Streptomyces bacteria in young tubers after the field experiment in 2014

\begin{tabular}{|c|c|c|c|c|}
\hline \multirow[b]{2}{*}{ Genus $^{\mathrm{y}}$} & \multicolumn{2}{|c|}{ Disease severity } & \multicolumn{2}{|c|}{$\begin{array}{c}\text { Pathogenic } \\
\text { Streptomyces bacteria }\end{array}$} \\
\hline & $\rho^{\mathrm{z}}$ & $P$ value & $\rho^{\mathrm{z}}$ & $P$ value \\
\hline Bacillus & -0.552 & 0.026 & -0.526 & 0.036 \\
\hline Uc Chitinophagaceae & -0.511 & 0.042 & -0.111 & 0.680 \\
\hline Uc Xanthomonadaceae & -0.764 & $<0.001$ & -0.447 & 0.082 \\
\hline Rhodanobacter & -0.720 & 0.001 & -0.526 & 0.036 \\
\hline Chitinophaga & -0.729 & 0.001 & -0.447 & 0.082 \\
\hline Burkholderia & -0.820 & $<0.001$ & -0.679 & 0.003 \\
\hline Streptomyces & -0.902 & $<0.001$ & -0.620 & 0.010 \\
\hline Uc Sphingobacteriales & -0.673 & 0.004 & -0.155 & 0.564 \\
\hline Shingomonas & -0.708 & 0.002 & -0.435 & 0.032 \\
\hline Uc Coxiellaceae & -0.752 & $<0.001$ & -0.247 & 0.356 \\
\hline
\end{tabular}

${ }^{\mathrm{y}} \mathrm{Uc}=$ unclassified. Taxa were based on the highest taxonomic level of resolution.

z Spearman's rank correlation value. 
A

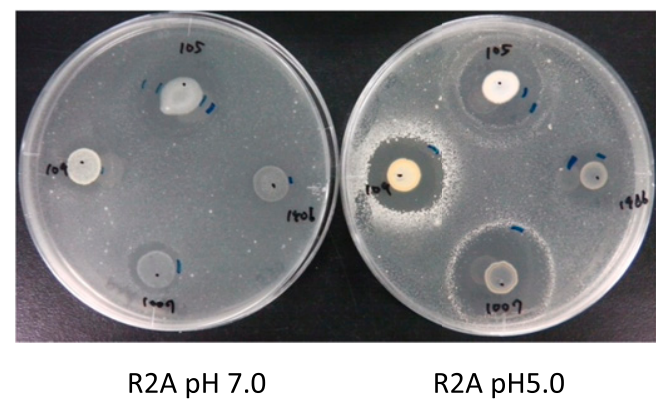

B

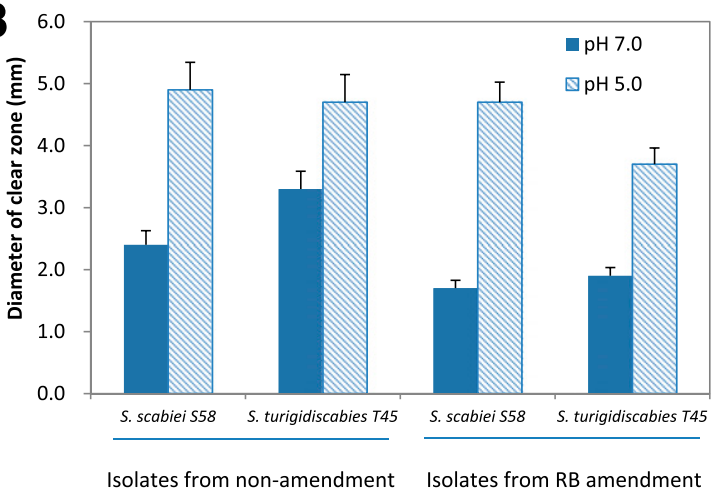

Fig. 2. Antagonistic activity of actinomycete isolates against pathogenic Streptomyces spp. A, Clear zones produced by antagonistic actinomycete isolates against the indicator bacterium (Streptomyces scabiei S58) on R2A medium plates at pH 7.0 and 5.0 (left and right plates, respectively). Spore suspensions of isolates ANA105, ANA109, ANA1007, and ANA1906 were dropped on the top, left, bottom, and right positions of each plate, respectively. Note that the clear zones on $\mathrm{R} 2 \mathrm{~A} \mathrm{pH} 5.0$ were larger than those on $\mathrm{pH} 7.0$. B, Effect of medium $\mathrm{pH}$ on the antagonistic activity of actinomycete isolates against $S$. scabiei S58 and S. turgidiscabies $\mathrm{T} 45$ as evaluated by the radius of the clear zone on R2A medium at $\mathrm{pH} 7.0$ and 5.0. The diameter of the inhibitory zone on the pH 5.0 medium was significantly greater than that on the $\mathrm{pH} 7.0$ medium (three-way analysis of variance, $P<0.001$ ). Inhibitory zones of isolates from the nonamendment soil were slightly but significantly greater than for the rice bran $(\mathrm{RB})$-amendment soil $(P=0.005)$ but there was no significant difference in the inhibitory zone diameters between S. scabiei S58 and S. turgidiscabies T45 $(P=0.972)$. Columns and error bars indicate means and standard deviation $(n=48)$, respectively.

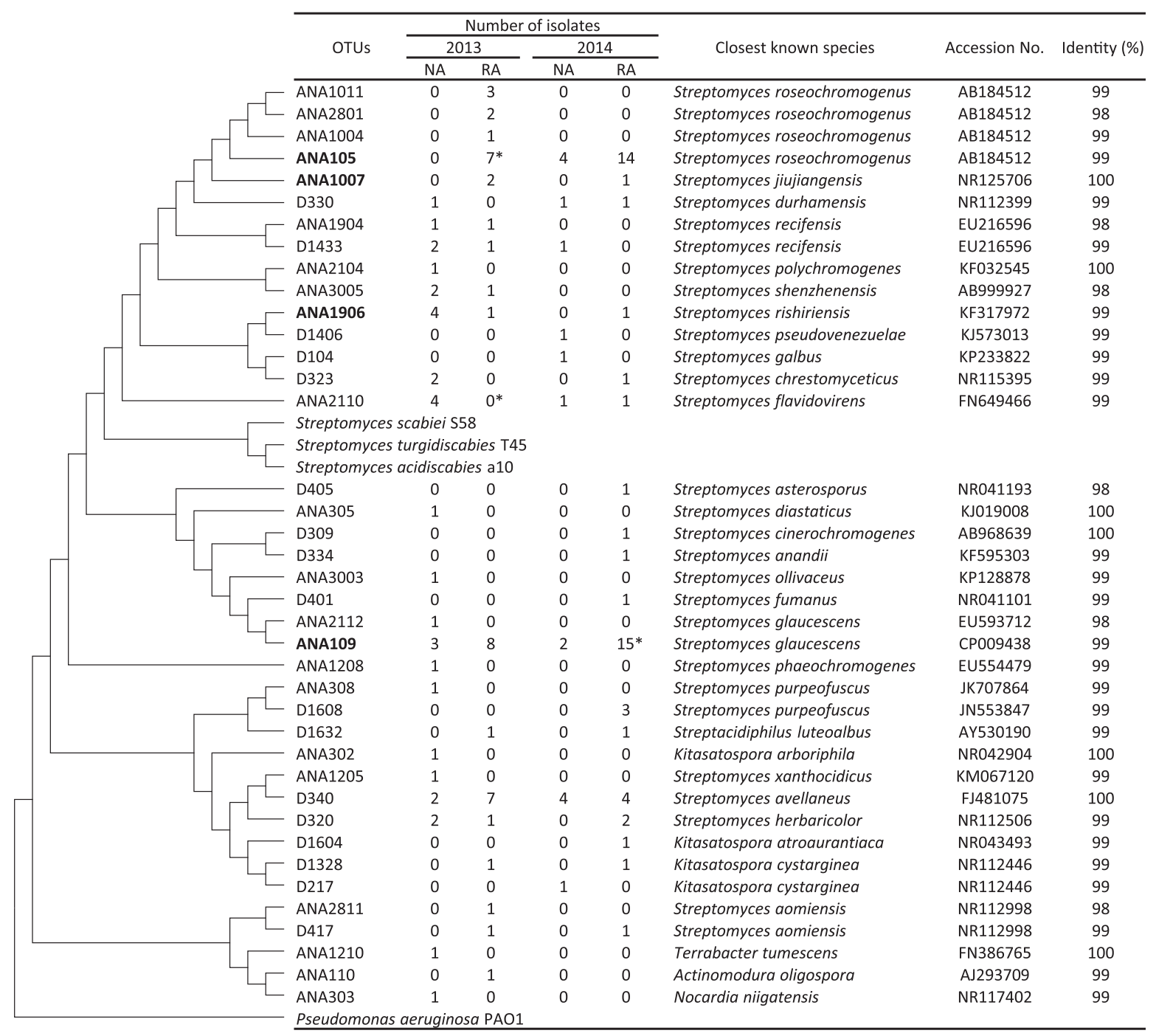

Fig. 3. Phylogenetic distribution of actinomycete isolates derived from nonamended (NA) and rice bran amended (RA) soils in the 2013 and 2014 experiments. The $16 \mathrm{~S}$ rRNA gene sequences in 140 actinomycete isolates (73 isolates in 2013 and 67 isolates in 2014) and three pathogenic Streptomyces spp. used in this study were determined, and they were assigned to 39 operational taxonomic units (OTU) by clustering with $\geq 99 \%$ identity. The dendrogram indicates the phylogenetic relationships among the representative sequences of OTU. Pseudomonas aeruginosa PAO1 was used as an outgroup. Asterisks indicate a significant difference $(P<$ 0.05) in the number of isolates for each OTU between the nonamended and RB-amended treatments using the compare algorithm in RDP (Wang et al. 2007). Strains used in the field inoculation test are indicated in bold. 
are often inconsistent among studies and their modes of action are not fully understood. The important role that soil microbes play in suppressing PCS has been generally accepted. This has been confirmed by some studies on naturally occurring common-scabsuppressive soils (Rosenzweig et al. 2012; Sagova-Mareckova et al. 2015).

The natural soil suppression of PCS is associated with low copy numbers of $\operatorname{txt} A B$, which is essential for the pathogenicity of PCS pathogens (Loria et al. 2006), in either the bulk soil or the rhizosphere (Sagova-Mareckova et al. 2015). The present study quantified the amount of $t x t A B$ in the tuber at the early tuber formation stage, which is a critical period for pathogen infection (Khatri et al. 2010, 2011). The results showed that RB amendment reduced PCS by repressing the pathogen population in the young tuber. Regression analyses of the results in 2014 showed that the amount of pathogenic Streptomyces bacteria in the young tubers at the early tuber formation stage was significantly correlated with disease severity. This fundamental correlation between disease severity and the densities of pathogenic Streptomyces bacteria in the tubers was probably identified for the first time because recently established methods for estimating the pathogen populations were used ( $\mathrm{Qu}$ et al. 2008). Our results suggest that RB amendment represses the growth of pathogens on the surface of young tubers. Furthermore, stepwise regression analyses revealed that disease severity was significantly explained by two factors: the amount of pathogenic Streptomyces bacteria in the young tuber and the population level of actinomycetes in the rhizosphere soil at the early tuber formation stage. Our data indicated that these two factors greatly affected the occurrence of PCS in RB-amended soil.

In the present study, molecular ecological analyses revealed that $\mathrm{RB}$ amendment decreased the diversity of the rhizosphere bacterial community but increased the relative abundance of certain groups of gram-positive bacterial populations, such as Streptomyces spp. Although the relative abundance of Streptomyces bacteria significantly increased after RB amendment at the genus level, not all Streptomyces spp. increased after RB amendment. More importantly, RB amendment increased the population of antagonistic Streptomyces spp. against PCS pathogens, suggesting that these

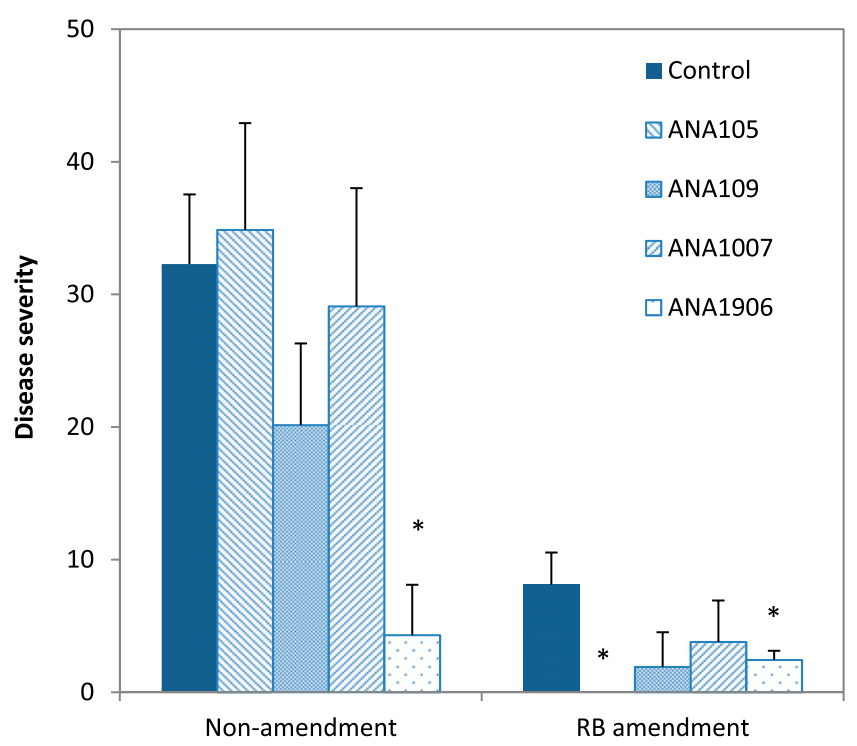

Fig. 4. Disease suppression effect after inoculations with Streptomyces isolates under field conditions. Four Streptomyces isolates (ANA105, ANA109, ANA1007, and ANA1906) derived from rice bran (RB)-amended soil were selected. Columns and error bars indicate the means and standard deviation $(n=4)$, respectively, and an asterisk on a column indicates a significant difference in disease severity (arcsine transformed) between the noninoculated control and those samples inoculated with an antagonistic strain under each amended condition when analyzed by the Wilcoxon signed rank test at $\alpha=0.5$. actinomycetes could potentially suppress PCS in the field. Thus, all data in the present study indicate that RB amendment exclusively increases certain groups of antagonistic Streptomyces spp. but suppresses the populations of pathogenic Streptomyces bacteria in the potato rhizosphere.

It has been reported that high population densities of antagonistic Streptomyces bacteria are associated with naturally occurring disease-suppressive soils (Kinkel et al. 2012) and PCS-resistant potato plant lines (Wanner 2007). It has also been demonstrated that the inoculation of seed tubers with antagonistic Streptomyces spp. can suppress PCS under field conditions (Kobayashi et al. 2012; Liu et al. 1995). The densities and the species compositions of antagonistic Streptomyces populations in a field soil would vary considerably depending on geological location, plant genetic diversities, soil nutritional levels, and so on (Kinkel et al. 2012; Otto-Hanson et al. 2013; Schlatter et al. 2013; Wiggins and Kinkel 2005). However, the present study clearly showed that RB amendment could be intentionally used to manipulate the microbial community toward increasing antagonism against PCS.

As shown in a number of previous studies, antagonistic microorganisms that were selected based on their antagonism under culture conditions often fail to control plant diseases in the field (Kinkel et al. 2012). However, the present study showed that the applications of antagonistic Streptomyces spp. could suppress PCS in the field. Among them, strain ANA 1906 had the greatest biocontrol stability under both nonamendment and RB-amendment conditions. Interestingly, the 16S rRNA gene sequence for strain ANA 1906 has 99\% identity to Streptomyces strain WoRs-501, which has been also been reported as an effective biocontrol agent for PCS (Kobayashi et al. 2015). Noticeably, the application of antagonistic Streptomyces sp. strain ANA105, whose population tends to increase after RB amendment, suppressed PCS only under $\mathrm{RB}$ amendment. As previously reported for the suppression of soilborne fungal diseases through an increase in actinobacteria by other organic amendments, such as chitin and seed meal (Cohen et al. 2005; Cretoiu et al. 2013), the present study also suggest that an increase of antagonistic Streptomyces population in a soil is directly linked to the suppression of PCS by RB. Interestingly, nitric oxide production by Streptomyces bacteria in Brassica napus seed meal amendments has been postulated to have a role in the induction of plant systemic resistance (Cohen et al. 2005). Therefore, RB may also act in the same way for decreasing the pathogenic Streptomyces population in young tubers by inducing plant systemic resistance.

The two most abundant Streptomyces spp. identified by the amplicon sequencing analysis in the RB-amended rhizosphere were different from the results obtained by culture-dependent isolation. It is well known that culture-dependent methods are biased because a microorganism can only be cultivated after its physiological niche has been identified (Ward et al. 1990). DNA extraction methods are also known as culture-independent methods (Feinstein et al. 2009). The differences in the abundances we observed might reflect the growth efficiency of actinomycetes on the R2A medium used for isolation or the soil sampling method (bulk or rhizosphere soil). However, the results from both the culture-dependent and -independent analyses suggested that disease suppression by the RB amendment could be partially explained by increases in the indigenous antagonistic Streptomyces populations in the potato rhizosphere.

There were power law relationships between the magnitude of increase by $\mathrm{RB}$ amendment and the number of genera at each magnitude in both 2013 and 2014. This indicated that only a small proportion of the rhizosphere bacterial community could be significantly altered by RB amendment. Power law relationships between the magnitude and frequency of an incident have been observed in various self-organized critical phenomena such as earthquakes (Bak and Tang 1989) and financial market fluctuations (Gabaix et al. 2003). Recently, it has also been postulated 
that soil-microbe complexes are self-organizing, and interactions and feedbacks between soil mineral constituents, organic matter, and microbial activity create and stabilize soil structure (Young and Crawford 2004). The bacterial community power law relationships we observed in the RB-amended rhizosphere might identify some of the relationships between the soil structure of volcanic ash soils and soil microorganisms after amendment with RB. It needs to be confirmed whether the microbial community shift and the power law relationships observed in the volcanic ash soil in our experimental field are applicable to other soil types such as redyellow soil.

Several gram-positive bacteria other than Streptomyces spp. such as Bacillus and Chitinophaga spp. also increased after RB amendment and were as negatively correlated with PCS disease severity as Streptomyces bacteria. However, their potential for disease suppression in the field was not investigated in the present study. The RB amendment increased the rhizosphere fungal population and affected community structure (T. Tomihama and S. Ikeda, unpublished data), which suggests that RB may also suppress PCS by changing the antagonistic fungal population. The possible contribution of other antagonistic microorganism groups responding to $\mathrm{RB}$ amendment should be investigated in the future.

Soil $\mathrm{pH}$, which is one of the factors that influences the occurrence of PCS, probably affects disease suppression by RB because soil actinomycete antagonism against $S$. scabiei and $S$. turgidiscabies was greater at $\mathrm{pH} 5.0$ than at 7.0. The application of calcium is also known to influence the incidence of PCS, presumably by promoting the growth of S. scabiei (Goto 1985; Lazarovits et al. 2007; Natsume et al. 2001). However, no definitive conclusions could be made in the present study due to the inappropriate experimental designs (small sample size and nonrepeated experiments). Therefore, the effects of soil $\mathrm{pH}$ and calcium application on PCS should be reassessed in a future study.

$\mathrm{RB}$ amendment has been reported to suppress the occurrence of sweet potato (Ipomoea batatas (L.) Lam.) soil rot disease caused by S. ipomoea (Kanaiso and Yonemoto 2003) and to have nematicidal activity against root-knot nematodes (Taba et al. 2008). These studies indicate that RB amendment could potentially contribute to sustainable agriculture in countries where rice is widely grown as a main crop.

\section{ACKNOWLEDGMENTS}

This study was partially supported by the Council for Science, Technology, and Innovation; the Cross-Ministerial Strategic Innovation Promotion Program; the "Technologies for creating next-generation agriculture, forestry and fisheries" program (funding agency: Bio-oriented Technology Research Advancement Institution, NARO); and Grants-in-Aid for Scientific Research (grant numbers 15H04620 and 15KT0037) from the Ministry of Education, Science, Sports, and Culture of Japan. We thank T. Mitsunaga at the NARO Agricultural Research Center for his statistical advice about the experimental design and analyses using JMP; K. Nakano and H. Katsumata at FASMAC Co., Ltd. for sequencing and statistically analyzing the samples; K. Noguchi at Katakura Coop Agri Co., Ltd. and N. Takahashi at Sunagro Co. Ltd. for their supply of organic materials and fertilizers; Editage for English language editing; and M. Terawaki, K. Yoshioka, H. Aradono, M. Ohsako, M. Yamashita, Y. Yamaguchi, M. Fukuyama, M. Hokazono, H. Taniguchi, and Y. Honda for their support in the field experiments.

\section{LITERATURE CITED}

Adams, M. J., and Lapwood, D. H. 1978. Studies on the lenticel development, surface microflora and infection by common scab (Streptomyces scabies) of potato tubers growing in wet and dry soils. Ann. Appl. Biol. 90:335-343.

Bak, P., and Tang, C. 1989. Earthquakes as a self-organized critical phenomenon. J. Geophys. Res. 94:15635-15637.

Benjamini, Y., and Hochberg, Y. 1995. Controlling the false discovery rate: A practical and powerful approach to multiple testing. J. R. Stat. Soc. Ser. B 57:289-300.
Bernard, E., Larkin, R. P., Tavantzis, S., Erich, M. S., Alyokhin, A., Sewell, G., Lannan, A., and Gross, S. D. 2012. Compost, rapeseed rotation, and biocontrol agents significantly impact soil microbial communities in organic and conventional potato production systems. Appl. Soil Ecol. 52: $29-41$.

Bonanomi, G., Antignani, V., Capodilupo, M., and Scala, F. 2010. Identifying the characteristics of organic soil amendments that suppress soilborne plant diseases. Soil Biol. Biochem. 42:136-144.

Caporaso, J. G., Kuczynski, J., Stombaugh, J., Bittinger, K., Bushman, F. D., Costello, E. K., Fierer, N., Peña, A. G., Goodrich, J. K., Gordon, J. I., Huttley, G. A., Kelley, S. T., Knights, D., Koenig, J. E., Ley, R. E., Lozupone, C. A., McDonald, D., Muegge, B. D., Pirrung, M., Reeder, J., Sevinsky, J. R., Turnbaugh, P. J., Walters, W. A., Widmann, J., Yatsunenko, T., Zaneveld, J., and Knight, R. 2010. QIIME allows analysis of highthroughput community sequencing data. Nat. Methods 7:335-336.

Caporaso, J. G., Lauber, C. L., Walters, W. A., Berg-Lyons, D., Huntley, J., Fierer, N., Owens, S. M., Betley, J., Fraser, L., Bauer, M., Gormley, N., Gilbert, J. A., Smith, G., and Knight, R. 2012. Ultra-high-throughput microbial community analysis on the Illumina HiSeq and MiSeq platforms. ISME J. 6:1621-1624.

Cohen, M. F., Yamasaki, H., and Mazzola, M. 2005. Brassica napus seed meal soil amendment modifies microbial community structure, nitric oxide production and incidence of Rhizoctonia root rot. Soil Biol. Biochem. 37: $1215-1227$.

Cole, J. R., Wang, Q., Cardenas, E., Fish, J., Chai, B., Farris, R. J., Kulam-Syed-Mohideen, A. S., McGarrell, D. M., Marsh, T., Garrity, G. M., and Tiedje, J. M. 2009. The Ribosomal Database Project: Improved alignments and new tools for rRNA analysis. Nucleic Acids Res. 37:D141-D145.

Collins, V. G., and Willoughby, L. G. 1962. The distribution of bacteria and fungal spores in Blelham Tarn with particular reference to an experimental overturn. Arch. Mikrobiol. 43:294-307.

Cretoiu, M. S., Korthals, G. W., Visser, J. H., and van Elsas, J. D. 2013. Chitin amendment increases soil suppressiveness toward plant pathogens and modulates the actinobacterial and oxalobacteraceal communities in an experimental agricultural field. Appl. Environ. Microbiol. 79:5291-5301.

Dees, M. W., and Wanner, L. A. 2012. In search of better management of potato common scab. Potato Res. 55:249-268.

Edgar, R. C. 2010. Search and clustering orders of magnitude faster than BLAST. Bioinformatics 26:2460-2461.

Feinstein, L. M., Sul, W. J., and Blackwood, C. B. 2009. Assessment of bias associated with incomplete extraction of microbial DNA from soil. Appl. Environ. Microbiol. 75:5428-5433.

Gabaix, X., Gopikrishnan, P., Plerou, V., and Stanley, H. E. 2003. A theory of power-law distributions in financial market fluctuations. Nature 423: $267-270$

Goto, K. 1985. Relationships between soil $\mathrm{pH}$, available calcium and prevalence of potato scab. Soil Sci. Plant Nutr. 31:411-418.

Han, J. S., Cheng, J. H., Yoon, T. M., Song, J., Rajkarnikar, A., Kim, W. G., Yoo, I. D., Yang, Y. Y., and Suh, J. W. 2005. Biological control agent of common scab disease by antagonistic strain Bacillus sp. sunhua. J. Appl. Microbiol. 99:213-221.

Haynes, K. G., Wanner, L. A., Thill, C. A., Bradeen, J. M., Miller, J., Novy, R. G., Whitworth, J. L., Corsini, D. L., and Vinyard, B. T. 2010. Common scab trials of potato varieties and advanced selections at three US locations. Am. J. Potato Res. 87:261-276.

Hiltunen, L. H., Ojanperä, T., Kortemaa, H., Richter, E., Lehtonen, M. J., and Valkonen, J. P. T. 2009. Interactions and biocontrol of pathogenic Streptomyces strains co-occurring in potato scab lesions. J. Appl. Microbiol. 106:199-212.

Hooker, W. J., ed. 1981. Compendium of Potato Diseases. American Phytopathological Society, St. Paul, MN.

Ikeda, S., Anda, M., Inaba, S., Eda, S., Sato, S., Sasaki, K., Tabata, S., Mitsui, H., Sato, T., Shinano, T., and Minamisawa, K. 2011. Autoregulation of nodulation interferes with impacts of nitrogen fertilization levels on the leaf-associated bacterial community in soybeans. Appl. Environ. Microbiol. 77:1973-1980

Kanaiso, Y., and Yonemoto, K. 2003. Influence of application of starch and rice bran into soil on both changes in microbial flora and occurrence of sweet potato soil rot disease and suppression of other organic materials against the disease. Bull Tokushima Pref. Agric. For. Fish Technol. Center 1:25-32. (In Japanese)

Katan, J. 2000. Physical and cultural methods for the management of soilborne pathogens. Crop Prot. 19:725-731.

Khatri, B. B., Tegg, R. S., Brown, P. H., and Wilson, C. R. 2010. Infection of Potato Tubers with the Common Scab Pathogen Streptomyces scabiei in a Soil-less System. J. Phytopathol. 158:453-455.

Khatri, B. B., Tegg, R. S., Brown, P. H., and Wilson, C. R. 2011. Temporal association of potato tuber development with susceptibility to common scab and Streptomyces scabiei-induced responses in the potato periderm. Plant Pathol. 60:776-786. 
Kinkel, L. L., Schlatter, D. C., Bakker, M. G., and Arenz, B. E. 2012. Streptomyces competition and co-evolution in relation to plant disease suppression. Res. Microbiol. 163:490-499.

Kobayashi, Y. O., Kobayashi, A., Maeda, M., Someya, N., and Takenaka, S. 2015. Biological control of potato scab and antibiosis by antagonistic Streptomyces sp. WoRs-501. J. Gen. Plant Pathol. 81:439-448.

Kobayashi, Y. O., Kobayashi, A., Maeda, M., and Takenaka, S. 2012. Isolation of antagonistic Streptomyces sp. against a potato scab pathogen from a field cultivated with wild oat. J. Gen. Plant Pathol. 78:62-72.

Lacey, M. J., and Wilson, C. R. 2001. Relationship of common scab incidence of potatoes grown in Tasmanian ferrosol soils with $\mathrm{pH}$, exchangeable cations and other chemical properties of those soils. J. Phytopathol. 149: 679-683.

Lambert, D. H., and Loria, R. 1989. Streptomyces scabies sp. nov., nom. rev. Int. J. Syst. Bacteriol. 39:387-392.

Lambert, D. H., and Manzer, F. E. 1991. Relationship of calcium to potato scab. Phytopathology 81:632-636.

Lapwood, D. H., Wellings, L. W., and Hawkins, J. H. 1973. Irrigation as a practical means to control potato common scab (Streptomyces scabies): Final experiment and conclusions. Plant Pathol. 22:35-41.

Larkin, R. P. 2008. Relative effects of biological amendments and crop rotations on soil microbial communities and soilborne diseases of potato. Soil Biol. Biochem. 40:1341-1351.

Larkin, R. P., Honeycutt, C. W., Griffin, T. S., Olanya, O. M., Halloran, J. M., and He, Z. 2011. Effects of different potato cropping system approaches and water management on soilborne diseases and soil microbial communities. Phytopathology 101:58-67.

Lazarovits, G. 2001. Management of soil-borne plant pathogens with organic soil amendments: A disease control strategy salvaged from the past. Can. J. Plant Pathol. 23:1-7.

Lazarovits, G., Hill, J., Patterson, G., Conn, K. L., and Crump, N. S. 2007. Edaphic soil levels of mineral nutrients, $\mathrm{pH}$, organic matter, and cationic exchange capacity in the geocaulosphere associated with potato common scab. Phytopathology 97:1071-1082.

Lazarovits, G., Tenuta, M., and Conn, K. L. 2001. Organic amendments as a disease control strategy for soilborne diseases of high-value agricultural crops. Australas. Plant Pathol. 30:111-117.

Liu, D., Anderson, N. A., and Kinkel, L. L. 1995. Biological control of potato scab in the field with antagonistic Streptomyces scabies. Phytopathology 85:827-831.

Loria, R., Kers, J., and Joshi, M. 2006. Evolution of plant pathogenicity in Streptomyces. Annu. Rev. Phytopathol. 44:469-487.

Matsumoto, K. 1979. A media for spore formation and a method for a long term preservation of potato scab pathogen. Plant Prot. 33:461-463. (In Japanese)

Miyajima, K., Tanaka, F., Takeuchi, T., and Kuninaga, S. 1998. Streptomyces turgidiscabies sp. nov. Int. J. Syst. Bacteriol. 48:495-502.

Narihiro, T., Tamaki, H., Akiba, A., Takasaki, K., Nakano, K., Kamagata, Y., Hanada, S., and Maji, T. 2014. Microbial community structure of relict niter-beds previously used for saltpeter production. PLoS One 9:e104752.

Natsume, M., Mizuto, T. A. K. I., Tashiro, N., and Hiroshi, A. B. E. 2001. Phytotoxin production and aerial mycelium formation by Streptomyces scabies and S. acidiscabies in vitro. J. Gen. Plant Pathol. 67:299-302.

Nishi, Y., Nakamura, M., and Iwai, H. 2015. Species-specific real-time quantitative polymerase chain reaction to quantify common scab pathogens in plants and soil in bottomless frame pots. Jpn. J. Phytopathol. 81:32-42. (in Japanese)
Otto-Hanson, L. K., Grabau, Z., Rosen, C., Salomon, C. E., and Kinkel, L. L. 2013. Pathogen variation and urea influence selection and success of Streptomyces mixtures in biological control. Phytopathology 103:34-42.

Qu, X., Wanner, L. A., and Christ, B. J. 2008. Using the TxtAB operon to quantify pathogenic Streptomyces in potato tubers and soil. Phytopathology 98:405-412.

Rosenzweig, N., Tiedje, J. M., Quensen, J. F., III, Meng, Q., and Hao, J. J. 2012. Microbial communities associated with potato common scabsuppressive soil determined by pyrosequencing analyses. Plant Dis. 96: 718-725.

Sagova-Mareckova, M., Daniel, O., Omelka, M., Kristufek, V., Divis, J., and Kopecky, J. 2015. Determination of factors associated with natural soil suppressivity to potato common scab. PLoS One 10:e0116291.

Sakamoto, Y., Hirata, K., Mori, K., Mukojima, M., Ogawa, T., Ohi, Y., Tamiya, S., Sohbaru, N., and Nakao, T. 2011. Resistance test method for potato common scab with non-bottom frame. Kyushu Plant Prot. Res. 57: 14-18.

Schlatter, D. C., DavelosBaines, A. L., Xiao, K. and Kinkel, L. L. 2013. Resource use of soilborne Streptomyces varies with location, phylogeny, and nitrogen amendment. Microb. Ecol. 66:961-971.

Singhai, P. K., Sarma, B. K., and Srivastava, J. S. 2011. Biological management of common scab of potato through Pseudomonas species and vermicompost. Biol. Control 57:150-157.

Taba, S., Sawada, J., and Moromizato, Z. 2008. Nematicidal activity of Okinawa Island plants on the root-knot nematode Meloidogyne incognita (Kofoid and White) Chitwood. Plant Soil 303:207-216.

Tamura, K., Stecher, G., Peterson, D., Filipski, A., and Kumar, S. 2013. MEGA6: Molecular evolutionary genetics analysis version 6.0. Mol. Biol. Evol. 30:2725-2729.

Tanaka, J., and Ikeda, S. 2002. Rapid and efficient DNA extraction method from various plant species using diatomaceous earth and a spin filter. Breed. Sci. 52:151-155.

Tashiro, N., Manabe, K., Saito, A., and Miyashita, K. 2012. Identification of potato scab-causing Streptomyces sp. occurring in strongly acidic soils in Saga Prefecture in Japan. J. Gen. Plant Pathol. 78:353-359.

Tomihama, T., Nsihi, Y., Ikenaga, M., Sakai, M., Okubo, T., and Ikeda, S. 2016. Draft genome sequences of Streptomyces scabiei S58, S. turgidiscabies T45 and S. acidiscabies a10, the pathogens of potato common scab isolated in Japan. Genome Announc. 4:e00062-16.

Wang, Q., Garrity, G. M., Tiedje, J. M., and Cole, J. R. 2007. Naive Bayesian classifier for rapid assignment of rRNA sequences into the new bacterial taxonomy. Appl. Environ. Microbiol. 73:5261-5267.

Wang, Y., and Qian, P. Y. 2009. Conservative fragments in bacterial 16S rRNA genes and primer design for $16 \mathrm{~S}$ ribosomal DNA amplicons in metagenomic studies. PLoS One 4:e7401.

Wanner, L. A. 2007. High proportions of nonpathogenic Streptomyces are associated with common scab-resistant potato lines and less severe disease. Can. J. Microbiol. 53:1062-1075.

Ward, D. M., Weller, R., and Bateson, M. M. 1990. 16S rRNA sequences reveal numerous uncultured microorganisms in a natural community. $\mathrm{Na}-$ ture 345:63-65.

Wiggins, B. E., and Kinkel, L. L. 2005. Green manures and crop sequences influence potato diseases and pathogen inhibitory activity of indigenous streptomycetes. Phytopathology 95:178-185.

Yamagata, M., and Ae, N. 1999. Direct acquisition of organic nitrogen by crops. Jpn. Agric. Res. Q. 33:15-22.

Young, I. M., and Crawford, J. W. 2004. Interactions and self-organization in the soil-microbe complex. Science 304:1634-1637. 